\title{
BMJ Open Effectiveness of drug interventions to prevent sudden cardiac death in patients with heart failure and reduced ejection fraction: an overview of systematic reviews
}

\author{
Muaamar Al-Gobari, ${ }^{1}$ Sinaa Al-Aqeel, ${ }^{2}$ François Gueyffier, ${ }^{3}$ Bernard Burnand ${ }^{1}$
}

To cite: Al-Gobari M, Al-Aqeel S, Gueyffier $\mathrm{F}$, et al. Effectiveness of drug interventions to prevent sudden cardiac death in patients with heart failure and reduced ejection fraction: an overview of systematic reviews. BMJ Open 2018;8:e021108. doi:10.1136/ bmjopen-2017-021108

- Prepublication history and additional material for this paper are available online. To view these files, please visit the journal online (http://dx.doi. org/10.1136/bmjopen-2017021108).

Received 11 December 2017 Revised 12 June 2018 Accepted 26 June 2018

Check for updates

(C) Author(s) (or their employer(s)) 2018. Re-use permitted under CC BY. Published by BMJ.

${ }^{1}$ Institute of Social and Preventive Medicine (IUMSP), Cochrane Switzerland, Lausanne University Hospital (CHUV), Lausanne, Switzerland ${ }^{2}$ Clinical Pharmacy Department, College of Pharmacy, King Saud University, Riyadh, Saudi Arabia ${ }^{3}$ Laboratoire de Biologie et Biométrie Evolutive-Equipe Modélisation des Effets Thérapeutiques, UMR 5558 Université Claude Bernard Lyon1, Lyon, France

Correspondence to Dr Muaamar Al-Gobari; muaamar.algobari@gmail.com

\section{ABSTRACT}

Objectives To summarise and synthesise the current evidence regarding the effectiveness of drug interventions to prevent sudden cardiac death (SCD) and all-cause mortality in patients with heart failure with reduced ejection fraction (HFrEF).

Design Overview of systematic reviews.

Data sources MEDLINE, Embase, ISI Web of Science and Cochrane Library from inception to May 2017; manual search of references of included studies for potentially relevant reviews.

Eligibility criteria for study selection We reviewed the effectiveness of drug interventions for SCD and all-cause mortality prevention in patients with HFrEF. We included overviews, systematic reviews and meta-analyses of randomised controlled trials of beta-blockers, angiotensinconverting enzyme inhibitors (ACE-i), angiotensin receptor blockers (ARBs), antialdosterones or mineralocorticoidreceptor antagonists, amiodarone, other antiarrhythmic drugs, combined ARB/neprilysin inhibitors, statins and fish oil supplementation.

Review methods Two independent reviewers extracted data and assessed the methodological quality of the reviews and the quality of evidence for the primary studies for each drug intervention, using Assessing the Methodological Quality of Systematic Reviews (AMSTAR) and Grading of Recommendations, Assessment, Development and Evaluation(GRADE), respectively. Results We identified 41 reviews. Beta-blockers, antialdosterones and combined ARB/neprilysin inhibitors appeared effective to prevent SCD and all-cause mortality. ACE-i significantly reduced all-cause mortality but not SCD events. ARBs and statins were ineffective where antiarrhythmic drugs and omega-3 fatty acids had unclear evidence of effectiveness for prevention of SCD and allcause mortality.

Conclusions This comprehensive overview of systematic reviews confirms that beta-blockers, antialdosterone agents and combined ARB/neprilysin inhibitors are effective on SCD prevention but not ACE-i or ARBs. In patients with high risk of $S C D$, an alternative therapeutic strategy should be explored in future research.

Systematic review registration PROSPERO 2017: CRD42017067442.
Strengths and limitations of this study

- A major strength of our study is that it summarises and synthesises the effectiveness of most evidence-based drug interventions in heart failure patients with reduced ejection fraction for sudden cardiac death (SCD) prevention and classified drug interventions according to the current evidence of their effectiveness.

- Our study used data from published studies and no data from unpublished studies.

- Our study reviews most heart failure drugs on the prevention of SCD and all-cause mortality but limited in scope for not including some drugs such as digoxin, ivabradine and non-drug interventions/devices such as implantable cardioverter defibrillators.

\section{INTRODUCTION}

Heart failure (HF) morbidity and mortality constitute an important burden for patients and for the healthcare systems in both developed and developing countries. ${ }^{1}$ Patients with $\mathrm{HF}$ are frequently hospitalised and have a high mortality risk because of a poor prognosis or an unexpected death, termed sudden cardiac death (SCD). In people diagnosed with HF, SCD occurs at 6-9 times the rate of the general population. Almost $20 \%$ and $80 \%$ of patients die within one year and eightyears of initial diagnosis, respectively. ${ }^{12}$ Risk factors of SCD were reported to be similar to cardiovascular diseases. However, the most studied and proven predictor of SCD in patients with $\mathrm{HF}$ is left ventricular ejection fraction. ${ }^{3}$ Potential drug interventions in patients with heart failure with reduced ejection fraction (HFrEF) include beta-blockers (BBs), angiotensin-converting enzyme inhibitors (ACEi), angiotensin receptor blockers (ARBs), antialdosterones or mineralocorticoid receptor antagonists, amiodarone, other 
antiarrhythmic agents, combined ARB/neprilysin inhibitors, statins and fish oil supplementation. ${ }^{4}$ Some of these interventions aimed at improving survival and reducing total mortality and SCD in HF. For instance, a newly licensed drug (sacubitril/valsartan) in PARADIGM-HF trial (Prospective Comparison of angiotensin neprilysin inhibitor (ARNI) with ACE-i to Determine Impact on Global Morbidity and Mortality in Heart Failure) showed around 20\% SCD reduction compared with enalapril. ${ }^{5}$

Nevertheless, optimal strategies for SCD prevention in $\mathrm{HF}$ are warranted if we take into account the high portion of mortality that still occurs in this population. Had a practitioner identified a patient with high risk of $\mathrm{SCD}$, it would be important to know which drug is effective or not in SCD prevention other than non-drug interventions such as implantable cardioverter defibrillators (ICDs). However, the large amount of information and the multiple and sometimes discordant systematic reviews on drug interventions could be misleading. ${ }^{6}$

Therefore, it is vital to identify the pharmacological agents that confer the greatest benefit in SCD risk reduction particularly in high-risk patients and if any optimisation of therapeutic strategies to those patients is possible accordingly. Thus, we decided to conduct an overview of systematic reviews to summarise and synthesise the available evidence about the effectiveness of drug interventions in the prevention of SCD in HFrEF and categorised the evidence into effective, ineffective and unclear evidence of effectiveness.

\section{METHODS}

We developed an a priori protocol for this review according to the Preferred Reporting Items for Systematic Reviews and Meta-Analyses statement (online supplementary file S1) and registered it in the PROSPERO International prospective register of systematic reviews (CRD42017067442).

\section{Data sources and search strategy}

Using the Ovid online interface, we searched MEDLINE (up to 24 May 2017), Embase (up to 23 May 2017), ISI Web of Science and the Cochrane Library (up to 24 May 2017). We identified overviews, systematic reviews and meta-analyses of randomised clinical trials by means of a search strategy (available on online supplementary file S2). The search strategy was composed of a filter, ${ }^{78}$ a mixture of Medical Subject Heading terms (MeSH and EMTREE in MEDLINE and Embase, respectively), text words as well as a truncation when possible without any language or publication date restriction. We did not search conference proceedings nor the grey literature. Reference lists of the included reviews were manually checked for any additional eligible studies. We contacted corresponding reviews' and primary studies' authors to seek for relevant unreported data. If judged necessary, we intended to update the included reviews by searching primary studies published after the systematic review publication date. Apart from authors' expertise in the field, we decided to update if the most up-to-date review of a drug intervention was published more than 5 years ago and/or new clinical trials are not integrated into the evidence.

\section{Selection criteria and data abstraction}

Studies were eligible if they were overviews, systematic reviews and meta-analyses of randomised clinical trials that evaluated the effectiveness of drug interventions in patients with HFrEF. Reviews were included if they examined the effectiveness of the following drugs: BBs, ACE-i, ARBs, antialdosterones or mineralocorticoid receptor antagonists, amiodarone, antiarrhythmics, combined $\mathrm{ARB} /$ neprilysin inhibitors, statins and fish oil supplementation. The selected reviews should have contained at least one of the aforementioned HF therapy and had evaluated SCD and/or all-cause mortality prevention as outcomes. We used Endnote and Rayyan ${ }^{9}$ to remove duplicates during the selection based on titles and abstracts, and full-text screening.

The abstracted data included eligibility criteria, population type, ejection fraction, study design (including intervention and comparator arms), follow-up duration and authors' evaluation of outcomes. Two reviewers (MA and SA) independently abstracted data. We resolved discrepancies by consensus or by adding a third reviewer's judgement when necessary.

\section{Quality assessment of the included reviews}

\section{Methodological quality of the included reviews}

Two authors (MA and SA) independently used the AMSTAR (Assessing the Methodological Quality of Systematic Reviews) measurement tool to assess systematic reviews included in our overview. The AMSTAR checklist comprises 11 questions (online supplementary S3 table) and each question accounted for one score point. ${ }^{10}$ The answer of 'yes' gave a score of 1 and zero otherwise. This increasingly adopted tool was used at the data collection step as stipulated in the overview protocol. ${ }^{11}$ If the authors of included reviews failed to publish their protocol, we deducted a score of one. In addition, we scored 'yes' if the authors mentioned that two reviewers were involved in the study screening, selection or data extraction.

\section{Quality of evidence in the included reviews}

Two authors (MA and SA) independently used the Grading of Recommendations, Assessment, Development and Evaluation (GRADE) approach ${ }^{12}$ to assess the quality of evidence of each intervention. GRADE is a widely accepted tool that allows the assessment of five key elements: risk of bias, inconsistency, indirectness, imprecision and publication bias. GRADE categorises the quality of evidence into four levels: high, moderate, low and very low. In the presence of a high risk of bias, the quality of the evidence is downgraded from high to moderate and so on. We also reported the GRADE assessments reported by the authors of the included reviews, or assessed them 
otherwise. Moreover, we did not reassess the risk of bias at primary study level if authors of included reviews had sufficiently assessed their quality. In the case of the updated review of ARBs, however, we assessed the quality of newly added randomised clinical trials and integrated it into the evidence synthesis.

\section{Statistical analysis and data synthesis}

We provided a narrative synthesis of the findings of the included reviews and if multiple reviews existed for the same intervention. However, in the case of ARBs, we updated the evidence and meta-analysed the data using random effects and fixed effects model with MantelHaenszel methods ${ }^{13}$ and reported random effects model to account for heterogeneity. Meanwhile, we evaluated each intervention against our outcomes of interest and synthesised the evidence taking into account heterogeneity and inconsistencies between reviews. As a rule of thumb, $\mathrm{I}^{2}$ (I-square) values of $25 \%, 50 \%$ and $75 \%$ correspond to low, moderate and high levels of heterogeneity, respectively. ${ }^{14}$

For the purpose of our overview, we categorised the evidence of the included interventions into three categories: (1) effective interventions; (2) ineffective interventions; and (3) uncertain evidence (conflicting or inconclusive evidence). We used odds ratios (OR) and relative effect or risk ratio (RR) as a summary statistic from the most recent or largest published systematic reviews, and confidence intervals (CIs) of $95 \%$ with a significance level determined at two-sided alpha less than $5 \%$.

\section{Patient and public involvement}

Our study did not involve direct contact with patients or the public.

\section{RESULTS}

\section{Search result}

According to our predefined eligibility criteria, our search strategy in electronic databases and manual searches resulted in 41 studies. ${ }^{6}{ }^{15-54}$ Figure 1 shows the search strategy results. At full-text level, we excluded studies that did not assess our outcome of interest $(n=129)$, were narrative reviews $(n=4)$, did

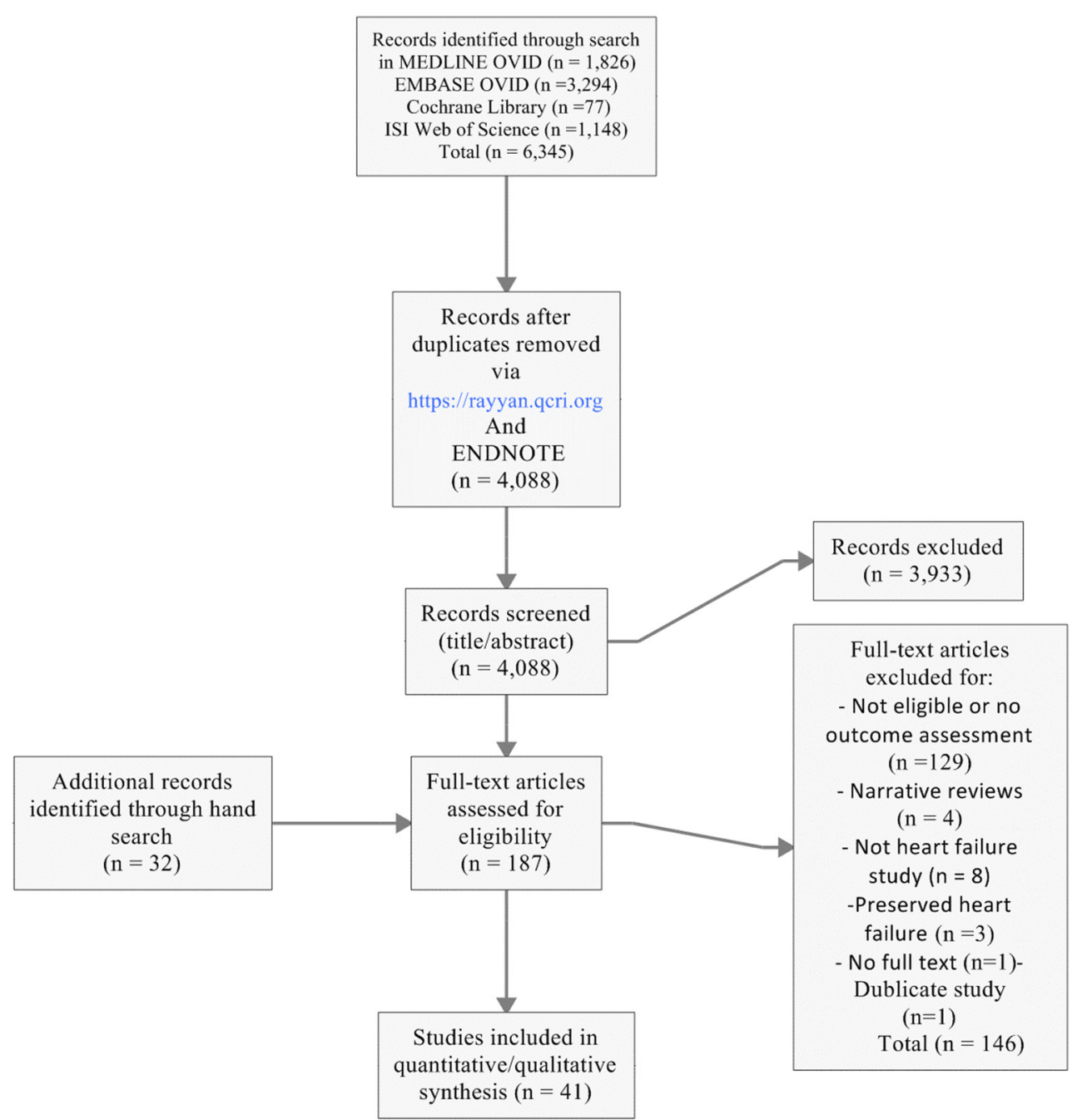

Figure 1 Flow chart for search result. 
not include HF patients $(n=8)$, included preserved patients with HF ( $n=3)$, were duplicate or had no full text $(\mathrm{n}=2)$.

\section{Characteristics of the included reviews}

As shown in table 1, the population of the included reviews consisted of HF patients with an ejection fraction $\leq 45 \%$ in most studies and a corresponding New York Heart Association classification ranging from I to IV. The effectiveness of each drug intervention has been assessed in at least one review. All reviews were systematic, except two reviews for antiarrhythmic drugs (AADs). At the time of their publication, 15 out of 41 reviews $(37 \%)$ had corresponding authors based in the USA, 7 (17\%) in Canada, $6(15 \%)$ in China, 3 in Chile, 2 in France, 2 in the UK and the 6 remaining in other countries.

The disclosure and reporting of financial resources or funding varied from one study to another. Twenty-one reviews $(51 \%)$ did not report the source of funding. Ten reviews $(24 \%)$ reported financial supports that included governments, academic institutions and device industry. Six reviews declared financial resources as none or no external funds. Three reviews reported industry sponsorship for at least one author. One review ${ }^{53}$ stated that one author obtained funds for the review without clarifying the source (online supplementary S4 table). We also reported findings summary of each review as stated by their respective authors (table 1 ).

\section{Risk of bias and quality of reviews}

As shown in table 1, the AMSTAR scores for quality assessment of the included reviews widely ranged from 2 to 10 (out of 11). All reviews had one score less because of non-listing of excluded primary studies except Cochrane reviews, ${ }^{27} 41$ which scored 10 because of non-inclusion of grey literature in the search strategy in one review and missing information for funding resources of included primary studies in another, cited respectively (online supplementary S3 table). We did not assess the AMSTAR score for six studies, of which two $^{4647}$ were narrative reviews, two ${ }^{25} 44$ were individual participant or patient data meta-analyses and the other two ${ }^{2632}$ were overviews of reviews.

The risk of bias of the included primary studies within reviews remained as judged by the original reviews' authors with the exception of the newly added randomised trials in the update of the ARBs review that we assessed (GRADE) (table 2). The quality of evidence for BBs and antialdosterone agents obtained a high quality on the GRADE scale, while ACE-i, amiodarone and statins obtained a moderate quality. However, combined $\mathrm{ARB} /$ neprilysin inhibitors had a moderate and high quality for SCD and all-cause mortality outcomes, respectively, whereas ARBs had a low quality of evidence (table 2).
Up-to-dateness of included reviews

Most retrieved evidence was published within the last 10 years (2008 and on), and seven (out of nine) drug interventions with updated systematic reviews were within the last 5 years (2012 and on). Moreover, we updated the pooled results for ARBs, which resulted in slightly different results compared with the original Cochrane review. ${ }^{27}$

\section{Effectiveness of interventions}

We report below the summaries of our evaluation on the effectiveness of the drug interventions considered that we have categorised into effective, ineffective and uncertain effectiveness (inconclusive or conflicting evidence).

\section{EFFECTIVE INTERVENTIONS \\ Beta-blockers}

Meta-analyses and systematic reviews of randomised controlled trials ${ }^{15-20}$ provided overwhelming evidence that BBs decrease the risk of SCD and all-cause mortality in patients with HFrEF. The quality of the evidence was rated high with a relative effect of 0.69 for SCD (OR, $95 \%$ CI $(0.62$ to 0.77$))$ and of 0.67 for all-cause mortality (OR, 95\% CI (0.59 to 0.76$)$ ) (table 2).

\section{Antialdosterone agents}

Published studies about mineralocorticoid receptor antagonists (antimineralocorticoids) or (so-called) antialdosterones appeared effective in SCD and all-cause mortality prevention. ${ }^{21} 2254$ However, in a recent systematic review, ${ }^{21}$ adverse effects (hyperkalaemia, degradation of renal function and gynaecomastia) were significantly higher in the antialdosterone-treated group compared with placebo. The quality of the evidence was rated high with relative effect for SCD (RR $0.81,95 \%$ CI (0.67 to 0.98$)$ ) and all-cause mortality (RR $0.81,95 \%$ CI (0.74 to 0.88$)$ ) (table 2$)$.

\section{ARB/neprilysin inhibitor}

One meta-analysis ${ }^{23}$ estimated the effects of combined neprilysin renin-aldosterone system inhibition and reported a reduction in SCD and all-cause mortality. The finding was principally derived from one RCT $(\text { PARADIGM-HF })^{5}$ that showed about $16 \%$ reduction of all-cause mortality in favour of sacubitril/valsartan (LCZ696 previously) compared with enalapril (an ACE-i). This mortality reduction was attributed to a decline on both SCD (20\%) and pump failure deaths. ${ }^{55}$ Table 2 shows the relative effect for SCD (RR 0.81, 95\% CI $(0.69$ to 0.95$))$ and all-cause mortality (RR 0.86 , $95 \%$ CI ( 0.79 to 0.94$))$. The moderate quality of the evidence for SCD outcome was due to the estimation from one single clinical trial and the absence of data from other included studies. All-cause mortality was, however, rated as high with a possibility of downgrading 


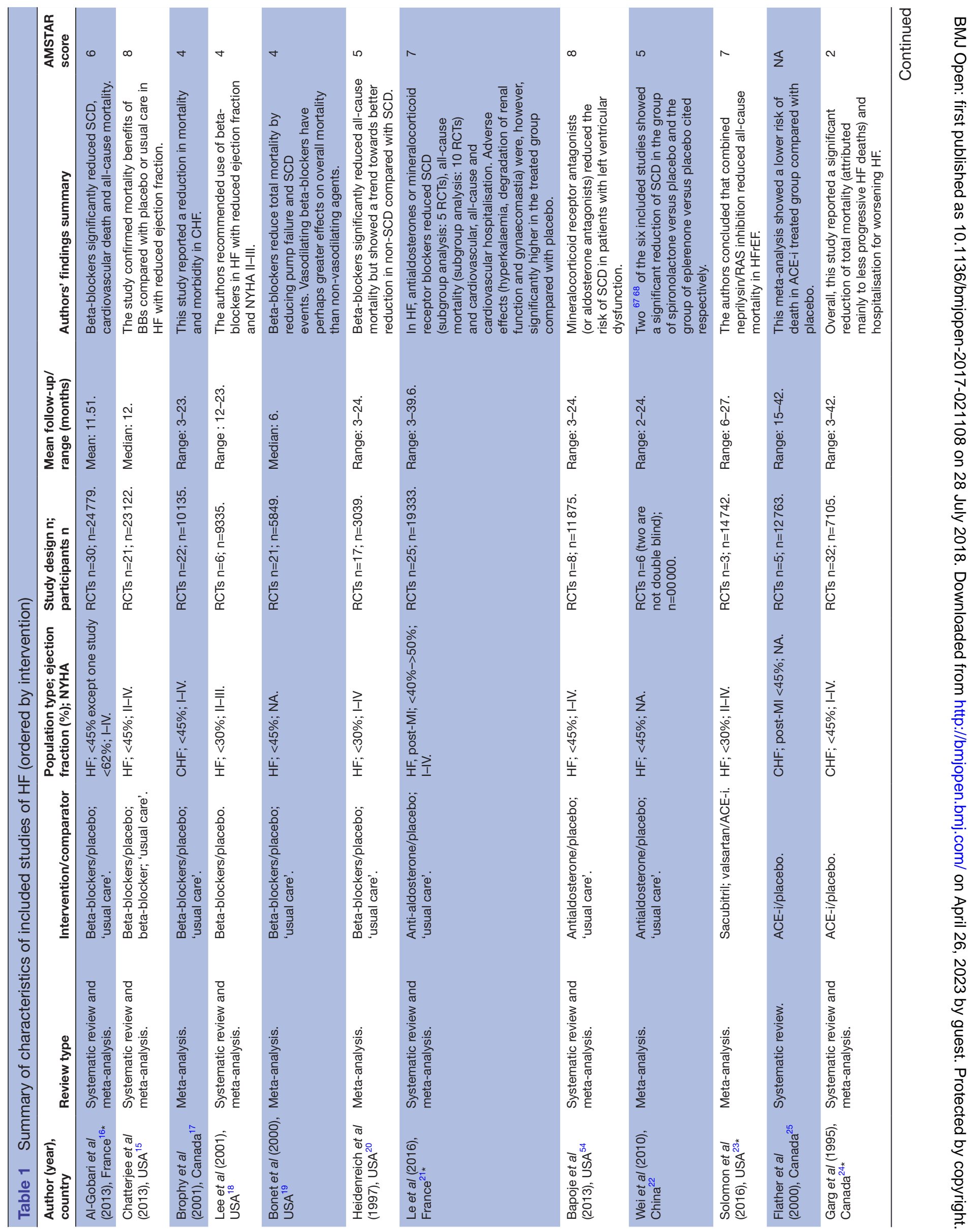




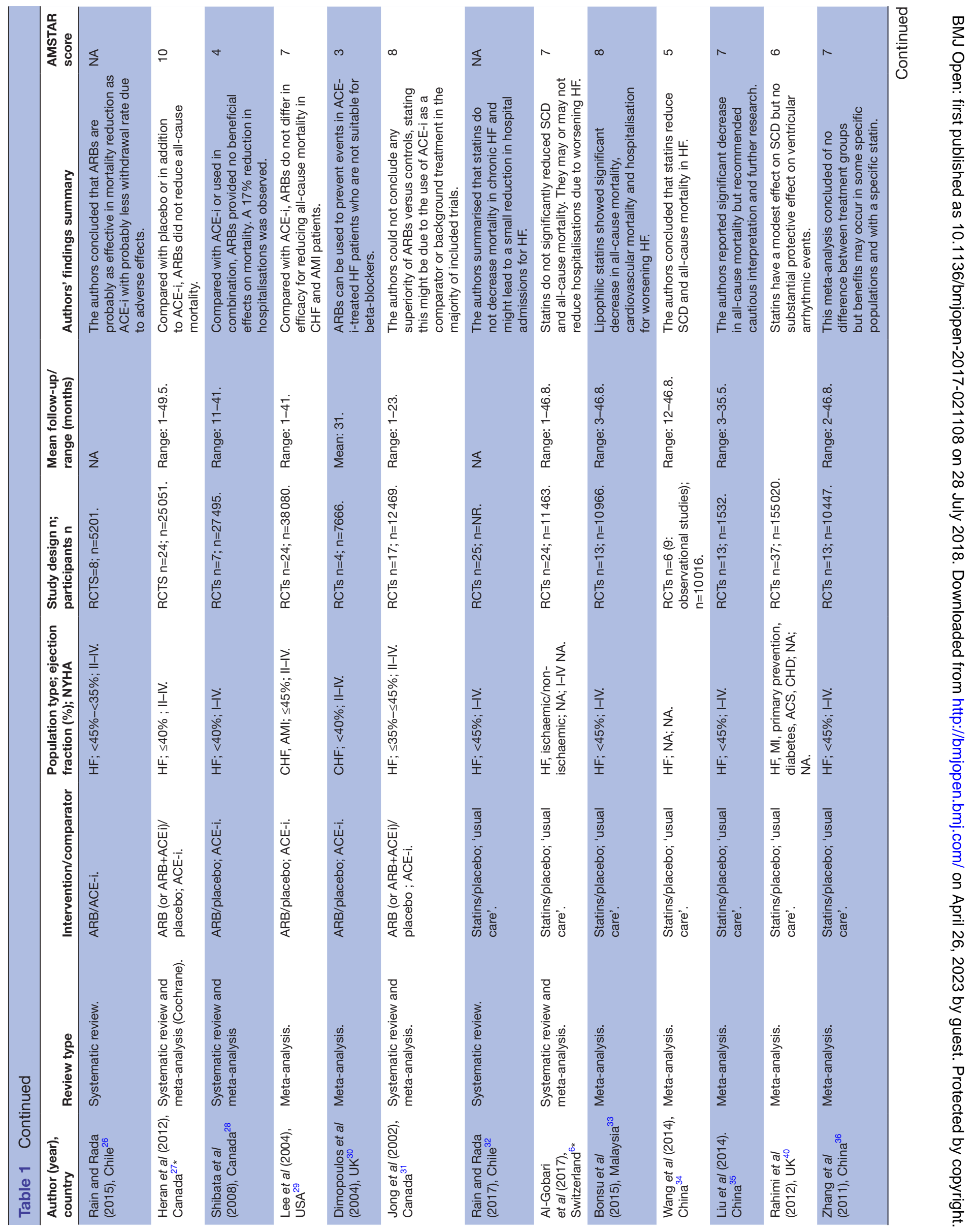




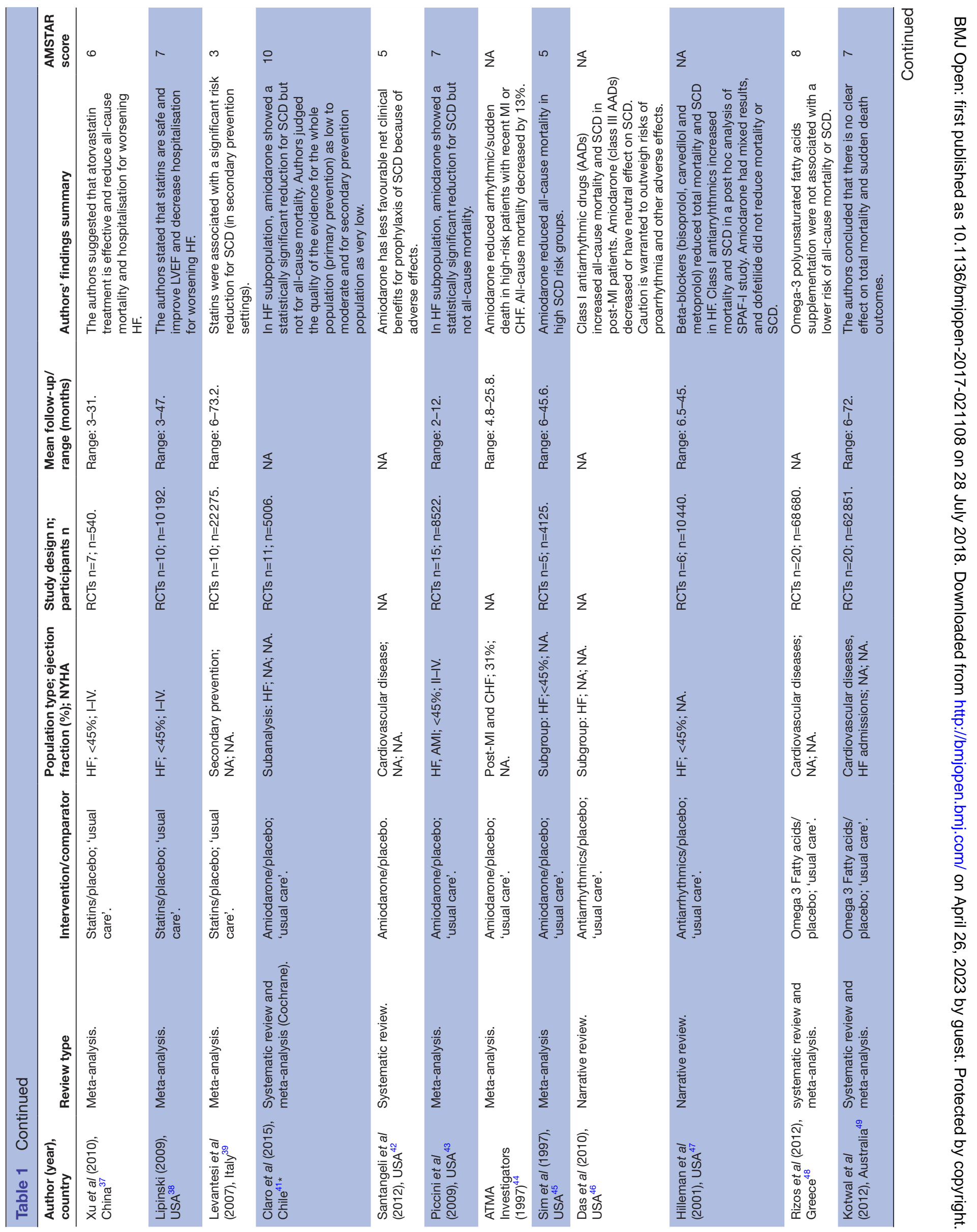


in case of a detectable publication bias or unestablished class effect.

\section{INEFFECTIVE INTERVENTIONS \\ ACE inhibitors}

Although two systematic reviews, ${ }^{24}{ }^{25}$ with an AMSTAR score of $2 / 11$ and $3 / 11$, respectively, reported a decline in total mortality and less progressive HF deaths, SCD events did not significantly decrease (OR $0.91,95 \%$ CI (0.73 to 1.12$))$. The quality of the evidence was rated as moderate because of the unclear or high risk of bias in included primary studies (table 2).

\section{Angiotensin receptor blockers}

As shown in figures 2 and 3, we updated a Cochrane review ${ }^{27}$ by including more eligible primary studies such as SUPPORT trial. ${ }^{56}$ Comparing ARBs with controls resulted in a slightly different effect size estimation. Eventually, we did not combine the different control groups to account for heterogeneity. In stratified analyses, ARBs compared with placebo remained ineffective for all-cause mortality (RR 0.79, 95\% CI (0.55 to 1.13)). Similarly, ARBs, compared with ACE-i or in combination versus ACE-i alone, were not superior in all-cause mortality reduction (RR $0.87,95 \%$ CI (0.56 to 1.36 ); RR $0.99,95 \%$ CI (0.90 to 1.09$)$, respectively) (figure 2$)$. The quality of the evidence is rated as low because of risk of bias, imprecision and inconsistency $\left(\mathrm{I}^{2} \approx 78, \mathrm{p}=0.010\right.$ for SCD outcome) (table 2). Data were limited for studies reporting $\mathrm{SCD}$, in particular those comparing $\mathrm{ARBs}$ versus placebo, or versus ACE-i (figure 2). In addition, the funnel plot for all-cause mortality outcome showed no evidence of publication bias (figure 4). No estimation of publication bias and no funnel plot was drawn for SCD as only five studies reported this outcome.

\section{Statins}

Published systematic reviews and meta-analyses about statins in HF were inconsistent ${ }^{632-40}$ with a recent tendency towards inefficacy in total mortality and SCD prevention. The quality of the evidence was rated as moderate because of a likelihood of publication bias revealed on the most up-to-date systematic review ${ }^{6}$ (table 2).

\section{UNCLEAR EVIDENCE OF EFFECTIVENESS}

The evidence of effectiveness of the drug interventions reported below was considered uncertain due either to conflicting or inconclusive evidence.

\section{Amiodarone and AADs}

Recently published systematic reviews ${ }^{41}{ }^{43}$ for amiodarone showed a significant reduction for SCD but not for all-cause mortality with less favourable net clinical benefits. ${ }^{42}$ Other older reviews ${ }^{44}$ of minor quality (AMSTAR of 3/11 and 5/11 cited respectively) reported a decline of both $S C D$ and all-cause mortality. 
Table 2 Summary of findings and GRADE evaluation for sudden cardiac death (SCD) and all-cause mortality prevention Drug interventions for SCD and all-cause mortality prevention in heart failure patients

\begin{tabular}{|c|c|c|c|c|c|c|c|}
\hline Outcome & Intervention/comparison & $\begin{array}{l}\text { Assumed } \\
\text { risk with } \\
\text { comparator }\end{array}$ & $\begin{array}{l}\text { Corresponding risk } \\
\text { with intervention }\end{array}$ & $\begin{array}{l}\text { Relative effect } \\
(95 \% \mathrm{Cl})\end{array}$ & $\begin{array}{l}\text { Number of } \\
\text { participants } \\
\text { (no. of studies) }\end{array}$ & $\begin{array}{l}\text { Quality of the } \\
\text { evidence } \\
\text { (GRADE) }\end{array}$ & Comments \\
\hline \multicolumn{8}{|l|}{$S C D$} \\
\hline & $\begin{array}{l}\text { Antialdosterone inhibitor/ } \\
\text { placebo; 'usual care' }\end{array}$ & 61 per 1000 & $\begin{array}{l}49 \text { per } 1000 \\
(41-60)\end{array}$ & $\begin{array}{l}\text { RR } 0.81 \\
(0.67 \text { to } 0.98)\end{array}$ & $\begin{array}{l}8301 \\
\text { (5 RCTs) }\end{array}$ & $\oplus \oplus \oplus \oplus \mathrm{High}^{*}$ & $I^{2}=8 \%(p=0.36)$ \\
\hline & ACE-i/placebo & 59 per 1000 & $\begin{array}{l}54 \text { per } 1000 \\
(43-65)\end{array}$ & $\begin{array}{l}\text { OR } 0.91 \\
(0.73 \text { to } 1.11)\end{array}$ & 6988 (30 RCTs) & $\begin{array}{l}\oplus \oplus \oplus \ominus \\
\text { Moderateł }\end{array}$ & $\mathrm{I}^{2}=0 \%(\mathrm{p}=0.94)$ \\
\hline & $\begin{array}{l}\text { ARB (or ARB+ACEi)/Placebo; } \\
\text { ACE-i }\end{array}$ & See comment & See comment & Not estimable & 13884 (5 RCTs) & $\begin{array}{l}\oplus \oplus \ominus \ominus \\
\text { Low } \ddagger \S\end{array}$ & $\begin{array}{l}\mathrm{l}^{2}=78 \%(\mathrm{p}=0.010) \\
\text { Overall, we did } \\
\text { not pool the } \\
\text { studies because of } \\
\text { heterogeneity }\end{array}$ \\
\hline & $\begin{array}{l}\text { Amiodarone/placebo; 'usual } \\
\text { care' }\end{array}$ & 118 per 1000 & $\begin{array}{l}93 \text { per } 1000 \\
(79-110)\end{array}$ & $\begin{array}{l}\text { RR } 0.79 \\
(0.67 \text { to } 0.93)\end{array}$ & 5006 (11 RCTs) & $\begin{array}{l}\oplus \oplus \ominus \ominus \\
\text { Low甲f }\end{array}$ & \\
\hline & $\begin{array}{l}\text { Omega } 3 \text { fatty acids/placebo; } \\
\text { 'usual care' }\end{array}$ & 93 per 1000 & $\begin{array}{l}88 \text { per } 1000 \\
(77-102)\end{array}$ & $\begin{array}{l}\text { RR } 0.94 \\
(0.82 \text { to } 1.09)\end{array}$ & 6975 (1 RCT) & $\begin{array}{l}\oplus \oplus \oplus \ominus \\
\text { Moderate† }\end{array}$ & \\
\hline
\end{tabular}

All-cause mortality

\begin{tabular}{|c|c|c|c|c|c|}
\hline Beta-blockers/placebo & 178 per 1000 & $\begin{array}{l}127 \text { per } 1000 \\
(113-141)\end{array}$ & $\begin{array}{l}\text { OR } 0.67 \\
(0.59 \text { to } 0.76)\end{array}$ & $\begin{array}{l}24779 \\
(26 \mathrm{RCTs})\end{array}$ & $\bigoplus \oplus \oplus \oplus \mathrm{High}^{\star} \quad \mathrm{I}^{2}=40 \%(p=0.02)$ \\
\hline $\begin{array}{l}\text { Antialdosterone inhibitor / } \\
\text { placebo; ' usual care' }\end{array}$ & 200 per 1000 & $\begin{array}{l}162 \text { per } 1000 \\
(148-176)\end{array}$ & $\begin{array}{l}\text { RR } 0.81 \\
(0.74 \text { to } 0.88)\end{array}$ & 9019 (10 RCTs) & $\oplus \oplus \oplus \oplus$ High $\quad I^{2}=0 \%(p=0.56)$ \\
\hline ARB; neprilysin inhibitor /ACE -i & 183 per 1000 & $\begin{array}{l}158 \text { per } 1000 \\
(145-172)\end{array}$ & $\begin{array}{l}\text { RR } 0.86 \\
(0.79 \text { to } 0.94)\end{array}$ & 14742 (3 RCTs) & $\oplus \oplus \oplus \oplus$ High $\quad I^{2}=0 \%(p=0.42)$ \\
\hline ACE-i/placebo & 219 per 1000 & $\begin{array}{l}178 \text { per } 1000 \\
(158-198)\end{array}$ & $\begin{array}{l}\text { OR } 0.77 \\
\text { (0.67 to } 0.88)\end{array}$ & 7105 (32 RCTs) & $\mathrm{I}^{2}=0 \%(\mathrm{p}=0.95)$ \\
\hline $\begin{array}{l}\text { ARB (or } A R B+A C E-i) / \text { placebo; } \\
\text { ACE-i. }\end{array}$ & 183 per 1000 & $\begin{array}{l}177 \text { per } 1000 \\
(161-197)\end{array}$ & $\begin{array}{l}\text { RR } 0.97 \text { (0.88 to } \\
1.08)\end{array}$ & 19510 (27 RCTs) & $I^{2}=24 \%(p=0.14)$ \\
\hline Statins/placebo; 'usual care' & 273 per 1000 & $\begin{array}{l}240 \text { per } 1000(205- \\
278)(233 \text { per } 1000 \\
(199-273))\end{array}$ & $\begin{array}{l}\text { RR } 0.88(0.75 \text { to } \\
1.02) \text { OR } 0.81 \\
(0.66 \text { to } 1)\end{array}$ & 11024 (13 RCTs) & $\mathrm{I}^{2}=37.7 \%(p=0.083)$ \\
\hline $\begin{array}{l}\text { Amiodarone/placebo; 'usual } \\
\text { care' }\end{array}$ & 264 per 1000 & $\begin{array}{l}237 \text { per } 1000 \\
(211-266)\end{array}$ & $\begin{array}{l}\text { RR } 0.90 \\
(0.80 \text { to } 1.01)\end{array}$ & 5006 (11 RCTs) & $\begin{array}{l}\oplus \oplus \ominus \ominus \\
\text { Low } 1 \ddagger\end{array}$ \\
\hline $\begin{array}{l}\text { Omega } 3 \text { fatty acids/ placebo; } \\
\text { 'usual care' }\end{array}$ & 291 per 1000 & $\begin{array}{l}274 \text { per } 1000 \\
(253-294)\end{array}$ & $\begin{array}{l}\text { RR } 0.94 \\
(0.87 \text { to } 1.01)\end{array}$ & 6975 (1 RCT) & $\begin{array}{l}\oplus \oplus \oplus \ominus \\
\text { Moderate }\end{array}$ \\
\hline
\end{tabular}

*Although graded high, this might be downgraded into moderate if we strictly consider the risk of bias of primary studies other than an overall estimation. †Estimation comes from one single clinical trial. No data obtained from other relevant studies for this outcome.

†The studies reported to generally have a moderate to high risk of bias due to allocation concealment and blinding reporting.

ףLikelihood of publication bias presence with an asymmetric funnel plot.

§Inconsistent results ranged from no effect to insignificant increase of events $\left(I^{2} \approx 71 \%\right)$.

${ }^{\star *}$ Most studies have small sample and wide Cls including no effect with appreciable harm or benefit.

ACE-i, ACE inhibitors; ARBs, angiotensin receptor blockers; GRADE, Grading of Recommendations, Assessment, Development and Evaluation; ${ }^{2}$, between-study variance due to heterogeneity; $R R$, risk ratio.

The quality of evidence for amiodarone was rated as low because of the unclear or high risk of bias and potential publication bias in primary studies (table 2). No systematic review for AADs of other classes or drugs (other than amiodarone) were retrieved. Nevertheless, two narrative reviews ${ }^{46}$ reported that class I antiarrhythmics increased SCD and all-cause mortality. These narrative reviews called for caution regarding the mixed results of amiodarone and its adverse effects.

\section{Omega-3 polyunsaturated fatty acids (PUFAs) and fish oil supplementation}

No systematic review was exclusively conducted in patients with $\mathrm{HF}$ for this intervention. One primary study, ${ }^{57}$ known as GISSI-Prevenzione HF, recruited patients with chronic HF and reported a lower mortality events in the n-3 PUFAs group compared with the placebo group. The authors reported an adjusted HR of 0.91 (95.5\% CI 0.833 to 0.998 ), $\mathrm{p}=0.041$ ). However, 
ARBs

Control

Odds Ratio Events Total Events Total Weight M-H, Fixed, 95\% Cl

Study or Subgroup 1.1.1 ARBs vs Placebo

ARCH-J 2003

CHARM-Alternative 2003

Crozier 1995

Mazayev 1998

Mitrovic 2003

Sharma 2000, III-In'|

Sharma 2000, III-US

SPICE 2000

STRECH 1999

Weber 1997

Subtotal $(95 \% \mathrm{Cl})$

Total events

$\begin{array}{rr}2 & 148 \\ 265 & 1013\end{array}$

$3144 \quad 1.2 \%$

$296 \quad 1015 \quad 87.4 \%$

$0 \quad 29 \quad 0.3 \%$

4125

175

$5 \quad 174$

3254

$4 \quad 237$

6179

$10 \quad 633$

$\begin{array}{rr}4 & 125 \\ 2963\end{array}$

304

Heterogeneity: $\mathrm{Chi}^{2}=9.87, \mathrm{df}=9(\mathrm{P}=0.36) ; \mathrm{I}^{2}=9 \%$

Test for overall effect: $Z=1.91(P=0.06)$

\subsubsection{ARBs vs ACE-i}

Dickstein 1995

ELITE 1997

ELITE II 2000

HEAVEN 2002

Lang 1997

Mazayev 1998

REPLACE 2001

RESOLVD 1999

Subtotal $(95 \% \mathrm{CI})$

Total events

Heterogeneity: $\mathrm{Chi}^{2}=11.47, \mathrm{df}=7(\mathrm{P}=0.12) ; \mathrm{l}^{2}=39 \%$

Test for overall effect: $Z=0.71(P=0.48)$

1.1.3 ARBs+ACE-i vs ACE-i alone

\begin{tabular}{|c|c|c|c|c|c|}
\hline ADEPT 2001 & 0 & 18 & 0 & 18 & \\
\hline CHARM-Added 2003 & 377 & 1276 & 412 & 1272 & $38.3 \%$ \\
\hline Hamroff 1999 & 0 & 16 & 1 & 17 & $0.2 \%$ \\
\hline RESOLVD 1999 & 29 & 332 & 4 & 109 & $0.7 \%$ \\
\hline SUPPORT 2015 & 98 & 578 & 85 & 568 & $9.4 \%$ \\
\hline Tonkon 2000 & 0 & 57 & 0 & 52 & \\
\hline V-HeFT 1999 & 2 & 55 & 0 & 28 & $0.1 \%$ \\
\hline Val-HeFT 2001 & 495 & 2511 & 484 & 2499 & $51.3 \%$ \\
\hline $\begin{array}{l}\text { Yasumura } 2004 \\
\text { Subtotal }(95 \% \mathrm{Cl})\end{array}$ & 1 & $\begin{array}{r}49 \\
4892\end{array}$ & 1 & $\begin{array}{r}57 \\
4620\end{array}$ & $\begin{array}{r}0.1 \% \\
100.0 \%\end{array}$ \\
\hline Total events & 1002 & & 987 & & \\
\hline \multicolumn{6}{|c|}{ Heterogeneity: $\mathrm{Chi}^{2}=6.98, \mathrm{df}=6(P=0.32) ; I^{2}=14 \%$} \\
\hline
\end{tabular}

Test for subgroup differences: $\mathrm{Chi}^{2}=3.77, \mathrm{df}=2(\mathrm{P}=0.15), \mathrm{I}^{2}=47.0 \%$

$0.64[0.11,3.91]$

$0.86[0.71,1.05]$

$2.19[0.11,41.72]$

$0.34[0.02,5.60]$

$0.62[0.12,3.31]$

$0.16[0.04,0.61]$

$0.47[0.12,1.92]$

$1.02[0.25,4.16]$

$3.37[0.43,26.49]$

$2.19[0.11,41.72]$

$0.84[0.70,1.00]$
Odds Ratio

M-H, Fixed, 95\% Cl
$0.53[0.07,3.85]$

$0.54[0.29,0.98]$

$1.14[0.95,1.38]$

$0.19[0.02,1.68]$

$6.90[0.38,125.83]$

$0.62[0.02,16.05]$

$0.51[0.09,2.81]$

$1.71[0.57,5.12]$

$1.06[0.90,1.26]$

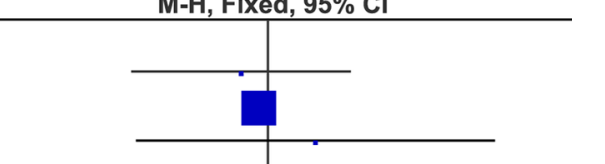

Not estimable

$0.88[0.74,1.04]$

$0.33[0.01,8.79]$

$2.51[0.86,7.31]$

$1.16[0.85,1.59]$

Not estimable

$2.66[0.12,57.39]$

$1.02[0.89,1.18]$

$1.17[0.07,19.16]$

$0.99[0.90,1.09]$
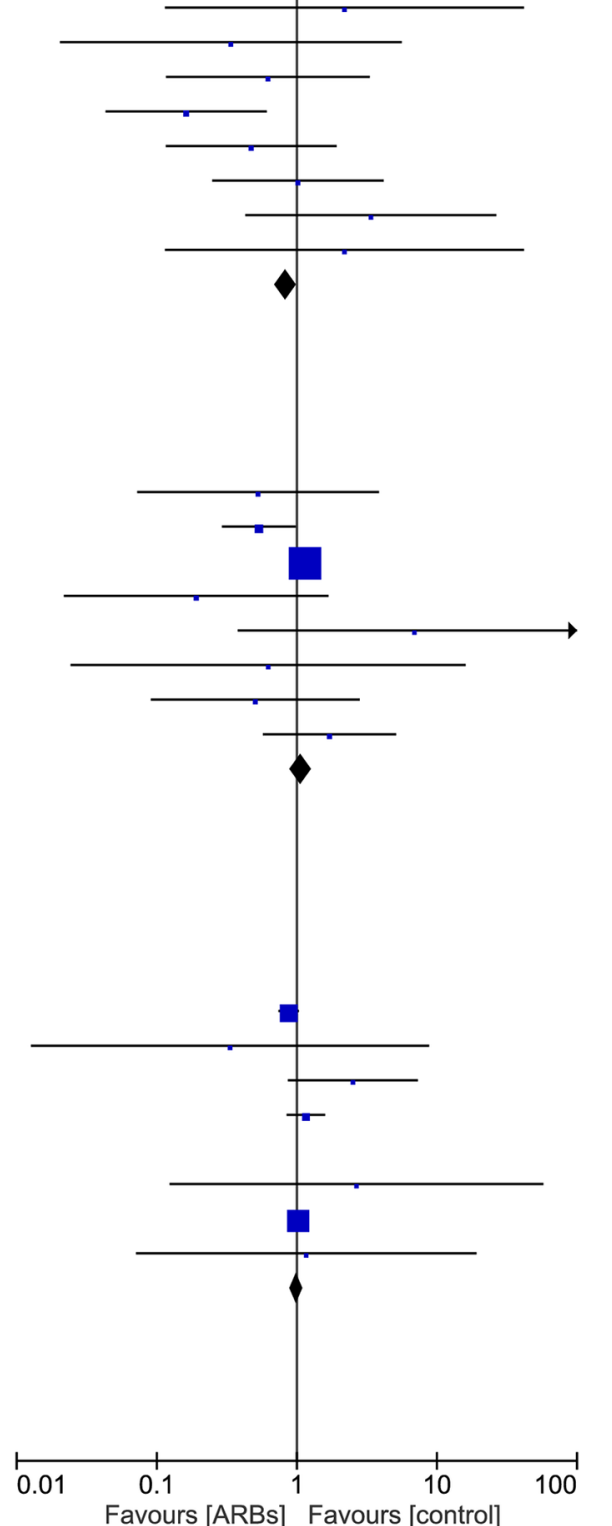

Figure 2 Efficacy of angiotensin receptor blockers (ARBs) compared with placebo, angiotensin-converting enzyme inhibitor (ACE-i) or combined in heart failure with reduced ejection fraction (HFrEF) for the prevention of all-cause mortality.

relative risk in our analysis remained statistically insignificant (RR 0.94, 95\% CI (0.87 to 1.01$), \mathrm{p}=0.10)$ and (RR $0.94,95 \%$ CI (0.81 to 1.09 ), $\mathrm{p}=0.42$ ) for all-cause mortality and SCD, respectively. Our assessment of the quality of the evidence involving GISSI-Prevenzione HF was moderate because of an absence of data of any other relevant studies (table 2). In addition, some recent systematic reviews ${ }^{4-51}$ included patients regardless of their cardiovascular disease and concluded of no clear effect, insufficient evidence or no reduction on SCD and all-cause mortality outcomes. Meanwhile, some older studies ${ }^{5253}$ reported that omega-3 fatty acids and fish oil supplements (other than $\alpha$-linolenic acid ${ }^{53}$ ) reduced SCD and all-cause mortality.

\section{DISCUSSION}

Our assessment of the effectiveness of drug interventions to prevent SCD in patients with HFrEF indicated that $\mathrm{BBs}$, antialdosterone agents, as well as combined $\mathrm{ARB} /$ neprilysin inhibitors were effective.

Previously reported meta-analyses and systematic reviews of RCTs ${ }^{15-20}$ indicated that $\mathrm{BBs}$ are effective in the prevention of SCD and all-cause mortality in HFrEF. 


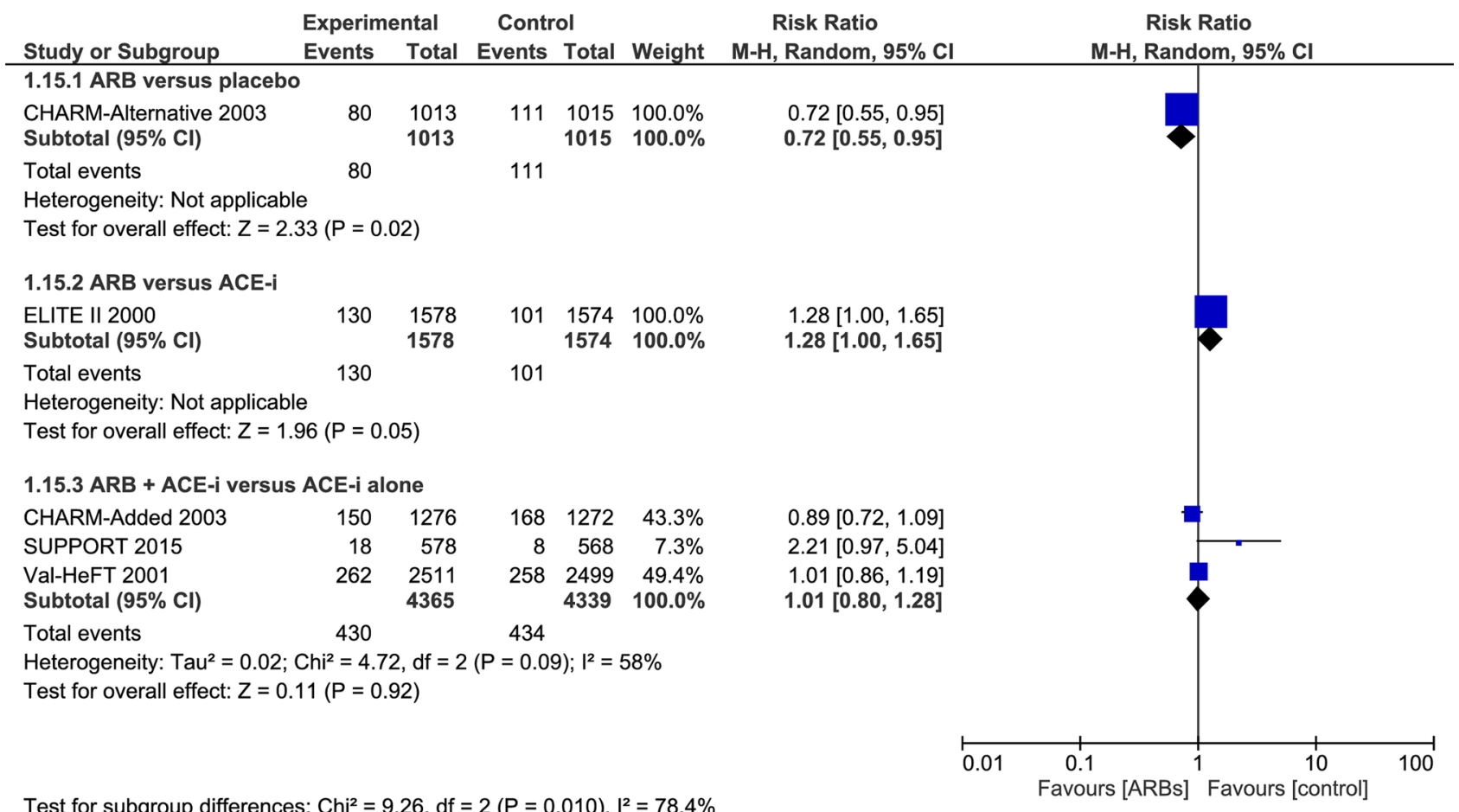

Figure 3 Efficacy of angiotensin receptor blockers (ARBs) compared with placebo, angiotensin-converting enzyme inhibitor (ACE-i) or combined in heart failure with reduced ejection fraction (HFrEF) for the prevention of sudden cardiac death (SCD).

However, although they were increasingly used as a usual 'routine' care in the compared arms of the more recently published clinical trials, ${ }^{58} \mathrm{BBs}$ stayed underused for long time and may still be. ${ }^{59}$ Mineralocorticoid receptor antagonists or antialdosterone drugs have been reported effective in HFrEF by reducing SCD and all-cause mortality. ${ }^{21225460}$ Our summary of the findings and the consistency of the results support this claim

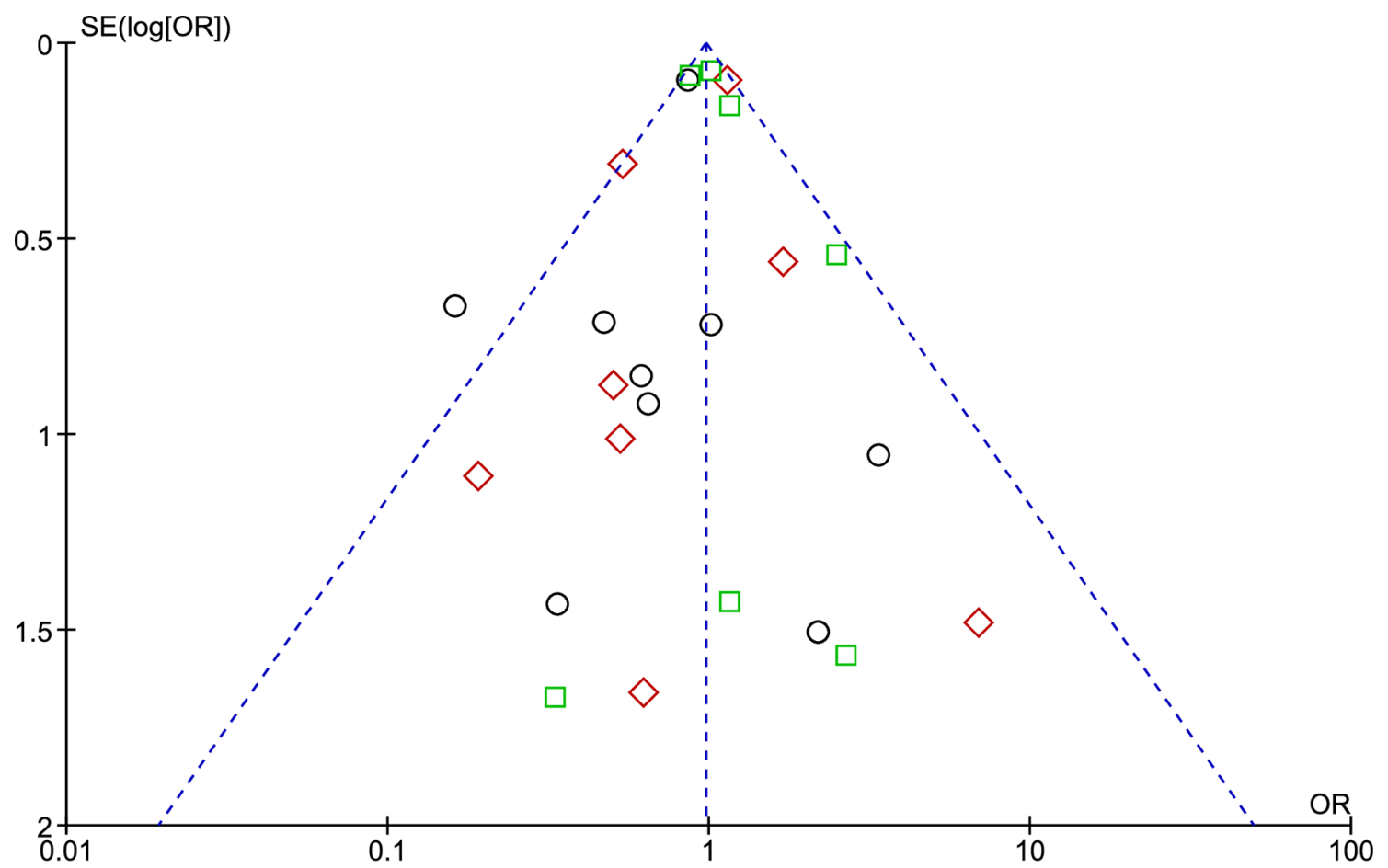
Subgroups
ARBs vs Placebo
ARBs vs ACE-i
ARBs+ACE-i vs ACE-i alone

Figure 4 Funnel plot of SE (log OR) by OR to evaluate publication bias for the efficacy of angiotensin receptor blockers (ARBs) compared with control in heart failure and reduced ejection fraction (HFrEF) for the prevention of all-cause mortality. 
with a high quality of evidence. Only one retrieved meta-analysis ${ }^{23}$ supported the effectiveness of combined $\mathrm{ARB} /$ neprilysin inhibitor. The authors acknowledged the limitation of their meta-analysis, which was not based on a systematic review, but merely pooling three well-known trials published in high impact journals (ie, IMPRESS, ${ }^{61}$ OVERTURE $^{62}$ and PARADIGM-HF). ${ }^{5}$ The quality of the evidence is, however, moderate for SCD and high for all-cause mortality, although our inability to assess any presence of a class effect or a potential publication bias.

We found that ACE-i showed a total mortality reduction in clinical trials and systematic reviews of patients with HF. ${ }^{24}{ }^{25}$ However, our overview showed that ACE-i, surprisingly, did not significantly decrease SCD with a moderate quality of evidence.

In addition, we found that neither ARBs nor statins reduced SCD and/or all-cause mortality. Our findings for ARBs were in agreement with Jong and colleagues, ${ }^{31}$ Shibata $e t a l^{28}$ and Dimopoulos et $a l^{30}$ but in contradiction to Lee $e t a l^{29}$ and Rain and Rada's conclusions. ${ }^{26}$ Our up-to-date meta-analysis for ARBs included only five primary studies, but large-scale trials, that reported SCD events. Eventually, we did not pool all the different comparators together but separately estimated the effect size for each group to account for the heterogeneity. Moreover, the addition of current trials such as SUPPORT ${ }^{56}$ improved the statistical power of detecting an effect if existed and the summary statistic remained statistically insignificant (figure 2). Of note, Jong and colleagues ${ }^{31}$ attributed this inefficacy of ARBs in HF to the background treatment with ACE-i.

Within the current evidence, ARBs should not be seen as interchangeable with ACE-i, which also showed a neutral effect on SCD, without a proper reason. Therefore, in a high-risk SCD patient, another therapeutic strategy should be sought, and an ARB/neprilysin inhibitor might be an alternative in patients similar to those of the PARADIGM-HF trial. ${ }^{5}$

The addition of statins to the therapy regimen of patients with HF had no survival benefits. Actually, a recent systematic review and meta-analysis indicated that statins did not reduce SCD nor all-cause mortality. ${ }^{6}$ Our current study reached the same conclusion with similar quality of evidence.

Our overview showed unclear evidence of effectiveness of omega-3 PUFAs, fish oil supplementation and AADs. The latter intervention had an evidence originated from only narrative reviews, as we did not identify any systematic reviews. Also, only one n-3 PUFA clinical trial $^{57}$ was conducted in patients with HF and reported a statistically significant mortality reduction; this result was not supported by other trials and recent systematic reviews, ${ }^{48-51}$ a finding that justified our conclusion of unclear evidence. Moreover, no other data or systematic reviews conducted in HF were retrieved by our electronic and manual searches.
AADs are classified into four categories ${ }^{46}$ : sodium channel blocking drugs (class I), BBs (class II), potassium channel blockers (class III) and calcium channel blockers (class IV). We found inconclusive evidence of effectiveness of all categories, with the exception of BBs. The evidence of effectiveness of class I, III and IV is inconclusive, neutral or even detrimental to patients as for class I AADs. ${ }^{46}$ Amiodarones, which present class I, II, III and IV effects, reported mixed results with potential SCD prevention with adverse effects ${ }^{43}$ and potentially, but rare, ${ }^{63}$ life-threatening proarrhythmias. ${ }^{46}$

Our overview has some limitations. First, we limited the scope of our study to drug treatment, thus excluding devices like ICDs. We believe that non-drug devices should be tackled in future research. European Society of Cardiology (ESC) Guideline (2016) ${ }^{64}$ and others (eg, www. uptodate.com) recommend the use of ICDs for only $\leq 35 \%$ of patients with HF and only after optimisation of drug therapy. In fact, SCDs occur in both reduced and preserved HF. Our overview might help to optimise therapy as a first step before introducing ICDs, which applies to a limited HF subpopulation, regardless of costs. Second, we may have failed to include other drug interventions used in HFrEF. Such drug candidates include digoxin, $\mathrm{I}_{\mathrm{f}}$-channel blockers (ivabradine), hydralazine/isosorbide dinitrate, nitroglycerin and phosphodiesterase 3 or 5 inhibitors. However, our overview included most commonly prescribed and evidence-based pharmacological therapy in HF as prespecified in our published protocol. ${ }^{11}$ Third, we did not use specific drug names in our literature search strategy, in order to avoid omitting a therapy that evaluated SCD and/or all-cause mortality prevention in patients with HF. Fourth, we based our analyses on existing systematic reviews and meta-analyses, and we updated only one meta-analysis. Consequently, we were unable to update the evidence for ACE-i. Furthermore, as indicated by the AMSTAR score, the methodological quality of some of the existing reviews was suboptimal. Fifth, we did not assess the safety of the evaluated drug interventions, nor the contraindications for their prescription, drug-drug interactions, as well as treatment adherence. Indeed, we considered that these important aspects were out of the scope of our analysis. Sixth, we were unable to do a sensitivity analysis, initially suggested in our protocol, for ischaemic versus non-ischaemic HF due to limited data availability. Finally, a potential source of bias relates to authors of this overview being the authors of three of the included reviews. ${ }^{16} 2165$ However, the adopted methodology is in line with systematic reviews guidelines and ensured a double check of data and methodological evaluation by at least two reviewers and a published protocol. ${ }^{11}$

It is noteworthy that high-quality evidence does not necessarily imply strong recommendations, and strong recommendations can arise from low-quality evidence. ${ }^{66}$ Therefore, when one intervention is graded high, it is not our intention to say that it is highly recommended, as we did not assess the level of recommendation in our study. In fact, a level of recommendation depends on the strength of evidence and (among others) on values and preferences of 
patients, net benefits and cost-effectiveness of a particular intervention.

\section{Implications for practice}

Our study summarises and synthesises the effectiveness of most evidence-based drug interventions in patients with HFrEF for SCD prevention. It classified drug interventions according to the current evidence of their effectiveness. This categorisation could help health professionals and patients making evidence-based decisions based on updated knowledge, particularly whenever a high-risk SCD patient is identified. Currently, there is no an established strategy to deal with patients at high risk of SCD. In such patients, a particular attention should be considered, and a careful selection of available therapeutic options is needed. Furthermore, there might be a shift towards an alternative therapeutic strategy based on SCD prevention-effective drugs in light of our findings.

\section{CONCLUSION}

Our overview indicates that only three drug interventions (BBs, antialdosterones, combined ARB/neprilysin inhibitors) significantly reduce $\mathrm{SCD}$ and improve overall survival among individuals with $\mathrm{HF}$ and reduced ejection fraction. However, there is no evidence of effectiveness of ARBs to reduce neither all-cause mortality nor SCD (with a low quality of evidence), and ACE-i do not significantly reduce SCD events. When the goal of drug therapy is to reduce SCD, especially in high-risk patients, our synthesis supports the use of the most effective regimen.

Acknowledgements We would like to thank Dr Emilie Zuercher for her technical assistance.

Contributors Design and conception: MA, FG and BB. MA is the guarantor. Project administration: BB. Writing original draft: MA. Critical analysis: all authors. Data curation: MA and SA. Statistical analysis: MA. Proofread and approved the final draft: all authors.

Funding MA, the corresponding author, received a financial grant (2014.0193) from The Federal Department of Economic Affairs, Education and Research (EAER), Switzerland, also from Département universitaire de médecine et santé communautaires (DUMSC), Lausanne university hospital (CHUV), Switzerland.

Disclaimer The former funders had no role in study design or conception, study analysis, writing or preparation of the manuscript.

Competing interests We declare that some authors of this overview are also authors of some of the included reviews. However, at least two reviewers systematically checked and validated the extracted data including study qualities. We declare that no other competing interests exist.

Patient consent Not required.

Provenance and peer review Not commissioned; externally peer reviewed.

Data sharing statement All data are available in the manuscript and its supported files. Any more information can be requested from the corresponding author.

Open access This is an open access article distributed in accordance with the Creative Commons Attribution 4.0 Unported (CC BY 4.0) license, which permits others to copy, redistribute, remix, transform and build upon this work for any purpose, provided the original work is properly cited, a link to the licence is given, and indication of whether changes were made. See: https://creativecommons.org/ licenses/by/4.0/.

\section{REFERENCES}

1. Thom T, Haase N, Rosamond W, et al. Heart disease and stroke statistics--2006 update: a report from the American Heart Association Statistics Committee and Stroke Statistics Subcommittee. Circulation 2006;113:e85-e151.

2. Tomaselli GF, Zipes DP. What causes sudden death in heart failure? Circ Res 2004;95:754-63.

3. Klein L, Hsia H. Sudden cardiac death in heart failure. Cardiol Clin 2014;32:135-44.

4. Ponikowski P, Voors AA, Anker SD, et al. 2016 ESC Guidelines for the diagnosis and treatment of acute and chronic heart failure: The Task Force for the diagnosis and treatment of acute and chronic heart failure of the European Society of Cardiology (ESC)Developed with the special contribution of the Heart Failure Association (HFA) of the ESC. Eur Heart J 2016;37:2129-200.

5. McMurray JJ, Packer M, Desai AS, et al. Angiotensin-neprilysin inhibition versus enalapril in heart failure. $N$ Engl $J$ Med 2014;371:993-1004.

6. Al-Gobari M, Le H-H, Fall M, et al. No benefits of statins for sudden cardiac death prevention in patients with heart failure and reduced ejection fraction: A meta-analysis of randomized controlled trials. PLoS One 2017:12:e0171168.

7. Lee E, Dobbins M, Decorby K, et al. An optimal search filter for retrieving systematic reviews and meta-analyses. BMC Med Res Methodol 2012;12:51.

8. Wilczynski NL, Haynes RB. Hedges Team. EMBASE search strategies achieved high sensitivity and specificity for retrieving methodologically sound systematic reviews. J Clin Epidemiol 2007;60:29-33.

9. Ouzzani M, Hammady H, Fedorowicz Z, et al. Rayyan-a web and mobile app for systematic reviews. Syst Rev 2016;5:210.

10. Shea BJ, Grimshaw JM, Wells GA, et al. Development of AMSTAR: a measurement tool to assess the methodological quality of systematic reviews. BMC Med Res Methodol 2007;7:10.

11. Al-Gobari M, Al-Aqeel S, Gueyffier F, et al. Effectiveness of drug interventions to prevent sudden cardiac death in patients with heart failure and reduced ejection fraction: an overview of systematic reviews. PROSPERO 2017 http://www.crd.york.ac.uk/PROSPERO/ display_record.asp?ID=CRD42017067442

12. Kunz R, Burnand B, Schünemann HJ, et al. Das GRADE-System. Der Internist 2008;49:673-80.

13. Mantel N, Haenszel W. Statistical aspects of the analysis of data from retrospective studies of disease. J Natl Cancer Inst 1959;22:719-48.

14. Higgins JP, Thompson SG, Deeks JJ, et al. Measuring inconsistency in meta-analyses. BMJ 2003;327:557-60.

15. Chatterjee $S$, Biondi-Zoccai G, Abbate $A$, et al. Benefits of $\beta$ blockers in patients with heart failure and reduced ejection fraction: network meta-analysis. BMJ 2013;346:f55.

16. Al-Gobari M, El Khatib C, Pillon F, et al. $\beta$-Blockers for the prevention of sudden cardiac death in heart failure patients: a meta-analysis of randomized controlled trials. BMC Cardiovasc Disord 2013:13:52.

17. Brophy JM, Joseph L, Rouleau JL. Beta-blockers in congestive heart failure. A Bayesian meta-analysis. Ann Intern Med 2001;134:550-60.

18. Lee S, Spencer A. Beta-blockers to reduce mortality in patients with systolic dysfunction: a meta-analysis. J Fam Pract 2001;50:499-504.

19. Bonet S, Agustí A, Arnau JM, et al. Beta-adrenergic blocking agents in heart failure: benefits of vasodilating and non-vasodilating agents according to patients' characteristics: a meta-analysis of clinical trials. Arch Intern Med 2000;160:621-7.

20. Heidenreich PA, Lee TT, Massie BM. Effect of beta-blockade on mortality in patients with heart failure: a meta-analysis of randomized clinical trials. J Am Coll Cardiol 1997;30:27-34.

21. Le HH, El-Khatib C, Mombled M, et al. Impact of Aldosterone Antagonists on Sudden Cardiac Death Prevention in Heart Failure and Post-Myocardial Infarction Patients: A Systematic Review and Meta-Analysis of Randomized Controlled Trials. PLoS One 2016;11.

22. Wei J, Ni J, Huang D, et al. The effect of aldosterone antagonists for ventricular arrhythmia: a meta-analysis. Clin Cardiol 2010;33:572-7.

23. Solomon SD, Claggett B, McMurray JJ, et al. Combined neprilysin and renin-angiotensin system inhibition in heart failure with reduced ejection fraction: a meta-analysis. Eur J Heart Fail 2016;18:1238-43.

24. Garg R, Yusuf S. Overview of randomized trials of angiotensinconverting enzyme inhibitors on mortality and morbidity in patients with heart failure. Collaborative Group on ACE Inhibitor Trials. JAMA 1995;273:1450-6.

25. Flather MD, Yusuf S, Køber L, et al. Long-term ACE-inhibitor therapy in patients with heart failure or left-ventricular dysfunction: a systematic overview of data from individual patients. ACEInhibitor Myocardial Infarction Collaborative Group. Lancet 2000;355:1575-81. 
26. Rain $\mathrm{C}, \mathrm{Rada} \mathrm{G}$. Is there any difference between angiotensin converting enzyme inhibitors and angiotensin receptor blockers for heart failure? Medwave 2015;15(Suppl 1):e6177.

27. Heran BS, Musini VM, Bassett K, et al. Angiotensin receptor blockers for heart failure. Cochrane Database Syst Rev 2012;141:Cd003040.

28. Shibata MC, Tsuyuki RT, Wiebe N. The effects of angiotensinreceptor blockers on mortality and morbidity in heart failure: a systematic review. Int J Clin Pract 2008;62:1397-402.

29. Lee VC, Rhew DC, Dylan M, et al. Meta-analysis: angiotensinreceptor blockers in chronic heart failure and high-risk acute myocardial infarction. Ann Intern Med 2004;141:693-704.

30. Dimopoulos K, Salukhe TV, Coats AJ, et al. Meta-analyses of mortality and morbidity effects of an angiotensin receptor blocker in patients with chronic heart failure already receiving an ACE inhibitor (alone or with a beta-blocker). Int J Cardiol 2004;93(23):105-11.

31. Jong P, Demers C, McKelvie RS, et al. Angiotensin receptor blockers in heart failure: meta-analysis of randomized controlled trials. J Am Coll Cardiol 2002;39:463-70.

32. Rain C, Rada G. Are statins beneficial for chronic heart failure? First update. Medwave 2017;17(Suppl2):e6853.

33. Osei Bonsu K, Reidpath DD, Kadirvelu A. Hydrophilic versus lipophilic statin therapy on outcomes in patients with heart failure: A systematic review and an adjusted indirect comparison metaanalysis of randomised trials. European Heart Journal 2015;36:546.

34. Wang JQ, Wu GR, Wang Z, et al. Long-term clinical outcomes of statin use for chronic heart failure: a meta-analysis of 15 prospective studies. Heart Lung Circ 2014;23:105-13.

35. Liu G, Zheng XX, Xu YL, YI X, et al. Effects of lipophilic statins for heart failure: a meta-analysis of 13 randomised controlled trials. Heart Lung Circ 2014;23:970-7.

36. Zhang S, Zhang L, Sun A, et al. Efficacy of statin therapy in chronic systolic cardiac insufficiency: a meta-analysis. Eur J Intern Med 2011;22:478-84.

37. Xu M, Yuan G, Wei F. Effect of atorvastatin in patients with chronic heart failure - insights from randomized clinical trials. Arch Med Sci 2010;6:866-73.

38. Lipinski MJ, Cauthen CA, Biondi-Zoccai GG, et al. Meta-analysis of randomized controlled trials of statins versus placebo in patients with heart failure. Am J Cardiol 2009;104:1708-16.

39. Levantesi G, Scarano M, Marfisi R, et al. Meta-analysis of effect of statin treatment on risk of sudden death. Am J Cardiol 2007:100:1644-50.

40. Rahimi K, Majoni W, Merhi A, et al. Effect of statins on ventricular tachyarrhythmia, cardiac arrest, and sudden cardiac death: a metaanalysis of published and unpublished evidence from randomized trials. Eur Heart J 2012;33:1571-81.

41. Claro JC, Candia R, Rada G, et al. Amiodarone versus other pharmacological interventions for prevention of sudden cardiac death. Cochrane Database Syst Rev 2015;12:CD008093.

42. Santangeli P, Di Biase L, Burkhardt JD, et al. Examining the safety of amiodarone. Expert Opin Drug Saf 2012;11:191-214.

43. Piccini JP, Berger JS, O'Connor CM. Amiodarone for the prevention of sudden cardiac death: a meta-analysis of randomized controlled trials. Eur Heart J 2009;30:1245-53.

44. Anon. Effect of prophylactic amiodarone on mortality after acute myocardial infarction and in congestive heart failure: meta-analysis of individual data from 6500 patients in randomised trials. Amiodarone Trials Meta-Analysis Investigators. Lancet 1997;350:1417-24.

45. Sim I, McDonald KM, Lavori PW, et al. Quantitative overview of randomized trials of amiodarone to prevent sudden cardiac death. Circulation 1997;96:2823-9.

46. Das MK, Zipes DP. Antiarrhythmic and nonantiarrhythmic drugs for sudden cardiac death prevention. J Cardiovasc Pharmacol 2010;55:1-49.

47. Hilleman DE, Bauman AL. Role of antiarrhythmic therapy in patients at risk for sudden cardiac death: an evidence-based review. Pharmacotherapy 2001;21:556-75.

48. Rizos EC, Ntzani EE, Bika E, et al. Association between omega-3 fatty acid supplementation and risk of major cardiovascular disease events: a systematic review and meta-analysis. JAMA 2012;308:1024-33.
49. Kotwal S, Jun M, Sullivan D, et al. Omega 3 Fatty acids and cardiovascular outcomes: systematic review and meta-analysis. Circ Cardiovasc Qual Outcomes 2012;5:808-18.

50. Kwak SM, Myung SK, Lee YJ, et al. Efficacy of omega-3 fatty acid supplements (eicosapentaenoic acid and docosahexaenoic acid) in the secondary prevention of cardiovascular disease: a meta-analysis of randomized, double-blind, placebo-controlled trials. Arch Intern Med 2012;172:686-94.

51. Chen $Q$, Cheng $L Q$, Xiao TH, et al. Effects of omega-3 fatty acid for sudden cardiac death prevention in patients with cardiovascular disease: a contemporary meta-analysis of randomized, controlled trials. Cardiovasc Drugs Ther 2011;25:259-65.

52. Marik PE, Varon J. Omega-3 dietary supplements and the risk of cardiovascular events: a systematic review. Clin Cardiol 2009;32:365-72.

53. Wang C, Harris WS, Chung M, et al. n-3 Fatty acids from fish or fishoil supplements, but not alpha-linolenic acid, benefit cardiovascular disease outcomes in primary- and secondary-prevention studies: a systematic review. Am J Clin Nutr 2006;84:5-17.

54. Bapoje SR, Bahia A, Hokanson JE, et al. Effects of mineralocorticoid receptor antagonists on the risk of sudden cardiac death in patients with left ventricular systolic dysfunction: a meta-analysis of randomized controlled trials. Circ Heart Fail 2013;6:166-73.

55. Desai AS, McMurray JJ, Packer M, et al. Effect of the angiotensinreceptor-neprilysin inhibitor LCZ696 compared with enalapril on mode of death in heart failure patients. Eur Heart J 2015;36:1990-7.

56. Sakata Y, Shiba N, Takahashi J, et al. Clinical impacts of additive use of olmesartan in hypertensive patients with chronic heart failure: the supplemental benefit of an angiotensin receptor blocker in hypertensive patients with stable heart failure using olmesartan (SUPPORT) trial. Eur Heart J 2015;36:915-23.

57. Tavazzi L, Maggioni AP, Marchioli R, et al. Effect of n-3 polyunsaturated fatty acids in patients with chronic heart failure (the GISSI-HF trial): a randomised, double-blind, placebo-controlled trial. Lancet 2008;372:1223-30.

58. Shen L, Jhund PS, Petrie MC, et al. Declining risk of sudden death in heart failure. N Engl J Med 2017;377:41-51.

59. Busson A, Thilly N, Laborde-Castérot $\mathrm{H}$, et al. Effectiveness of guideline-consistent heart failure drug prescriptions at hospital discharge on 1-year mortality: Results from the EPICAL2 cohort study. Eur J Intern Med 2018;51:53-60.

60. Anand K, Mooss AN, Mohiuddin SM. Aldosterone inhibition reduces the risk of sudden cardiac death in patients with heart failure. $J$ Renin Angiotensin Aldosterone Syst 2006;7:15-19.

61. Rouleau JL, Pfeffer MA, Stewart DJ, et al. Comparison of vasopeptidase inhibitor, omapatrilat, and lisinopril on exercise tolerance and morbidity in patients with heart failure: IMPRESS randomised trial. Lancet 2000;356:615-20.

62. Packer M, Califf RM, Konstam MA, et al. Comparison of omapatrilat and enalapril in patients with chronic heart failure: the Omapatrilat Versus Enalapril Randomized Trial of Utility in Reducing Events (OVERTURE). Circulation 2002;106:920-6.

63. Doggrell SA. Amiodarone -- waxed and waned and waxed again. Expert Opin Pharmacother 2001;2:1877-90.

64. Ponikowski P, Voors AA, Anker SD, et al. 2016 ESC Guidelines for the diagnosis and treatment of acute and chronic heart failure: The Task Force for the diagnosis and treatment of acute and chronic heart failure of the European Society of Cardiology (ESC). Developed with the special contribution of the Heart Failure Association (HFA) of the ESC. Eur J Heart Fail 2016;18:891-975.

65. Al-Gobari M, Le HH, Fall M, et al. No benefits of statins for sudden cardiac death prevention in patients with heart failure and reduced ejection fraction: A meta-analysis of randomized controlled trials. PLoS One 2017:12:e0171168.

66. Guyatt GH, Oxman AD, Vist GE, et al. GRADE: an emerging consensus on rating quality of evidence and strength of recommendations. BMJ 2008;336:924-6.

67. Pitt B, Zannad F, Remme WJ, et al. The Effect of Spironolactone on Morbidity and Mortality in Patients with Severe Heart Failure. N Engl J Med Overseas Ed 1999;341:709-17.

68. Pitt B, Remme W, Zannad F, et al. Eplerenone, a selective aldosterone blocker, in patients with left ventricular dysfunction after myocardial infarction. N Engl J Med 2003;348:1309-21. 